\title{
Inhaled nitric oxide therapy and risk of renal dysfunction: a systematic review and meta-analysis of randomized trials
}

\author{
Sheng-Yuan Ruan ${ }^{1,2^{*}}$, Tao-Min Huang ${ }^{1}$, Hon-Yen Wu ${ }^{1,3}$, Huey-Dong $W^{2}{ }^{2}$, Chong-Jen Y $u^{2}$ and Mei-Shu Lai ${ }^{1^{*}}$
}

\begin{abstract}
Introduction: Inhaled nitric oxide (iNO) is an important therapy for acute respiratory distress syndrome (ARDS), pulmonary hypertension and pediatric hypoxemic respiratory failure. Safety concerns regarding iNO and renal dysfunction have been reported; however, there are currently no systematic reviews on this issue. Our objective was to evaluate published randomized controlled trials (RCTs) to ascertain the risk of renal dysfunction associated with iNO therapy in patients with and without ARDS.
\end{abstract}

Methods: A systematic review of databases was performed to identify RCTs which compared iNO with controls up to September 2014. Effect estimates for risk ratio (RR) of acute kidney injury (AKI) were pooled using a random-effects model.

Results: Ten RCTs involving 1363 participants were included. Inhaled nitric oxide significantly increased the risk of AKI compared with controls (RR, 1.4, 95\%Cl, 1.06 to $1.83, p=0.02$ ). In the stratified analysis, a high cumulative-dose of iNO significantly increased the risk of $A K I(R R, 1.52,95 \% \mathrm{Cl}, 1.14$ to $2.02, \mathrm{p}=0.004)$, whereas medium and low cumulative-doses did not (RR, $0.64,95 \% \mathrm{Cl}, 0.23$ to 1.81 and $\mathrm{RR}, 0.56,95 \% \mathrm{Cl}, 0.11$ to 2.86 respectively). In subgroup analysis by study population, an increased risk of AKI was observed in patients with ARDS (RR, 1.55, 95\%Cl, 1.15 to $2.09, \mathrm{p}=0.005)$ but not in those without (RR, $0.90,95 \% \mathrm{Cl}, 0.49$ to $1.67, \mathrm{p}=0.75)$.

Conclusions: The available data show that iNO therapy may increase the risk of renal dysfunction, especially with prolonged use and in patients with ARDS. The risk in pediatric population is unknown owing to limited data. We suggest monitoring renal function during iNO therapy, and that future trials of iNO should evaluate renal safety.

\section{Introduction}

Nitric oxide was first reported to be an endogenous vasodilator in 1987 [1]. Soon after this discovery, inhaled nitric oxide (iNO) was applied to treat pulmonary hypertension and various pulmonary diseases [2,3]. Previous studies and clinical trials have shown that iNO possesses the therapeutic effects of selective pulmonary vasodilatation without causing systemic hypotension, and an effect on improving ventilation-perfusion mismatch $[3,4]$. Currently, iNO has been an important treatment modality for pulmonary hypertension, acute respiratory distress

\footnotetext{
*Correspondence: syruan@ntu.edu.tw; mslai@ntu.edu.tw

${ }^{1}$ Institute of Epidemiology and Preventive Medicine, National Taiwan

University, No.17 Xu-Zhou Road, Taipei 10020, Taiwan

2Division of Pulmonary and Critical Care Medicine, Department of Internal

Medicine, National Taiwan University Hospital, Taipei, Taiwan

Full list of author information is available at the end of the article
}

syndrome (ARDS), and pediatric hypoxemic respiratory failure [5-7].

Cumulative data from physiological studies and clinical trials suggest that iNO therapy has a good safety profile [8-10], and that its potential adverse effects, including methemoglobinemia, inhibition of platelet aggregation and systemic vasodilatation, are usually clinically insignificant $[8,11,12]$. However, a safety concern about renal dysfunction for nitric oxide inhalation was reported in a metaanalysis designed to evaluate the efficacy of iNO in ARDS [13]. This finding contradicts earlier evidence that iNO has favorable effects on renal and splanchnic perfusion [8]. In addition, this adverse effect, as a class effect of iNO therapy, was not observed in non-ARDS populations. These contrasting findings warrant further investigation to clarify the association between iNO and the risk of renal dysfunction in patients with and without ARDS. 
Therefore, we conducted this systematic review and metaanalysis to ascertain the risk of acute kidney injury (AKI) in iNO therapy and to investigate whether the risk varies among different patient populations.

\section{Materials and methods Search strategy}

This systematic review was conducted using an a priori published protocol submitted to the PROSPERO website (Registration number CRD42013005731) and reported according to the Preferred Reporting Items for Systematic Reviews and Meta-Analyses (PRISMA) criteria [14]. No institutional review board approval or consents were needed for this systematic review because it evaluated published studies. We searched MEDLINE via the NCBI Entrez system and Cochrane Central Register of Controlled Trials up to 25 September 2014. Bibliographies of retrieved studies and recent review articles were also screened to identify additional trials. Both keywords and $\mathrm{MeSH}$ terms searches were used to identify relevant citations. The search terms were "inhaled nitric oxide" AND "randomized controlled trial", and MeSH terms were "Nitric Oxide/therapeutic use" [Mesh] AND "Randomized Controlled Trial" [Publication Type]. There were no language restrictions. Details of our search strategy are shown in the online appendix (see Additional file 1). The eligible studies were parallel randomized controlled trials (RCTs) comparing patients who did and did not receive iNO therapy. The exclusion criteria included crossover trials and studies not reporting AKI in the results.

\section{Study selection and data extraction}

Two investigators (SYR and TMH) screened studies for inclusion and independently extracted data from the included studies. Any disagreements were resolved by discussion. A standardized recording form was used for data extraction.

\section{Assessment of risk of bias}

Quality assessment of these studies was done using the Cochrane Collaboration tool for assessing the risk of bias [15]. We assessed the risk of bias associated with random sequence generation, allocation concealment, blinding of participants and personnel, blinding of outcome assessments, incomplete outcome data, selective outcome reporting, and other bias. Two investigators (SYR and TMH) independently assessed the risk of bias in the individual studies, and discrepancies were resolved by consensus.

\section{Outcome measures}

The primary outcome of interest was AKI as defined in the individual studies regardless of the severity of injury.
The secondary outcome was AKI requiring renal replacement therapy (RRT). Risk ratio (RR) was used as a measurement of association in the analysis.

\section{Stratified analysis}

Stratified analysis by study population was performed to investigate whether the risk of iNO-associated renal dysfunction varied among different patient populations. To test the dose-response relationship between iNO and the risk of renal dysfunction, stratified analysis by duration and dosage of iNO therapy was also performed.

\section{Data synthesis}

Outcome measures were pooled using a random-effects model with the inverse variance method because of anticipated heterogeneity among the included studies. We analyzed data by intention-to-treat analysis and calculated the point estimates and $95 \%$ CI of the summary effect. When one arm of a study contained no events, 0.5 was added to all cells of the two-by-two table [16]. Sensitivity analysis was performed to check the robustness of the effect estimate using different data synthesis models. The Peto method was used in the sensitivity analysis because of its advantage of a less biased estimate for summary effect in the settings of sparse data and imbalance of trial size [17]. Because the Peto method can only be used to calculate odds ratios (ORs), we also calculated ORs using a random-effects model to compare the effect sizes obtained by these two methods. Heterogeneity was explored using the Q-statistic and $\mathrm{I}^{2}$. Heterogeneity was considered low, moderate, and high according to $\mathrm{I}^{2}$ values of $<25 \%, 25$ to $50 \%$ and $>50 \%$, respectively [18]. Publication bias was evaluated by a funnel plot of standard error versus RR based on the primary outcome, and with Egger's test [19]. For all analyses, a two-sided $P$-value $<0.05$ was considered to be statistically significant. The data were analyzed using Stata software, version 11 (StataCorp, Texas, USA).

\section{Results}

\section{Literature search and study characteristics}

Through the electronic searches and from references, 252 citations were identified. According to our predefined inclusion and exclusion criteria, 10 RCTs involving a total of 1,363 patients were included in the final analysis [12,20-28]. To calculate the risk for incident AKI, 26 patients were excluded from the analysis because they had received hemodialysis before the enrollment of trials. The number of studies evaluated at each stage of the literature review is shown in Figure 1. Quality assessment (see Additional file 2) of the included studies suggested a low risk of bias, except for one study which was published with an abstract [21]. 


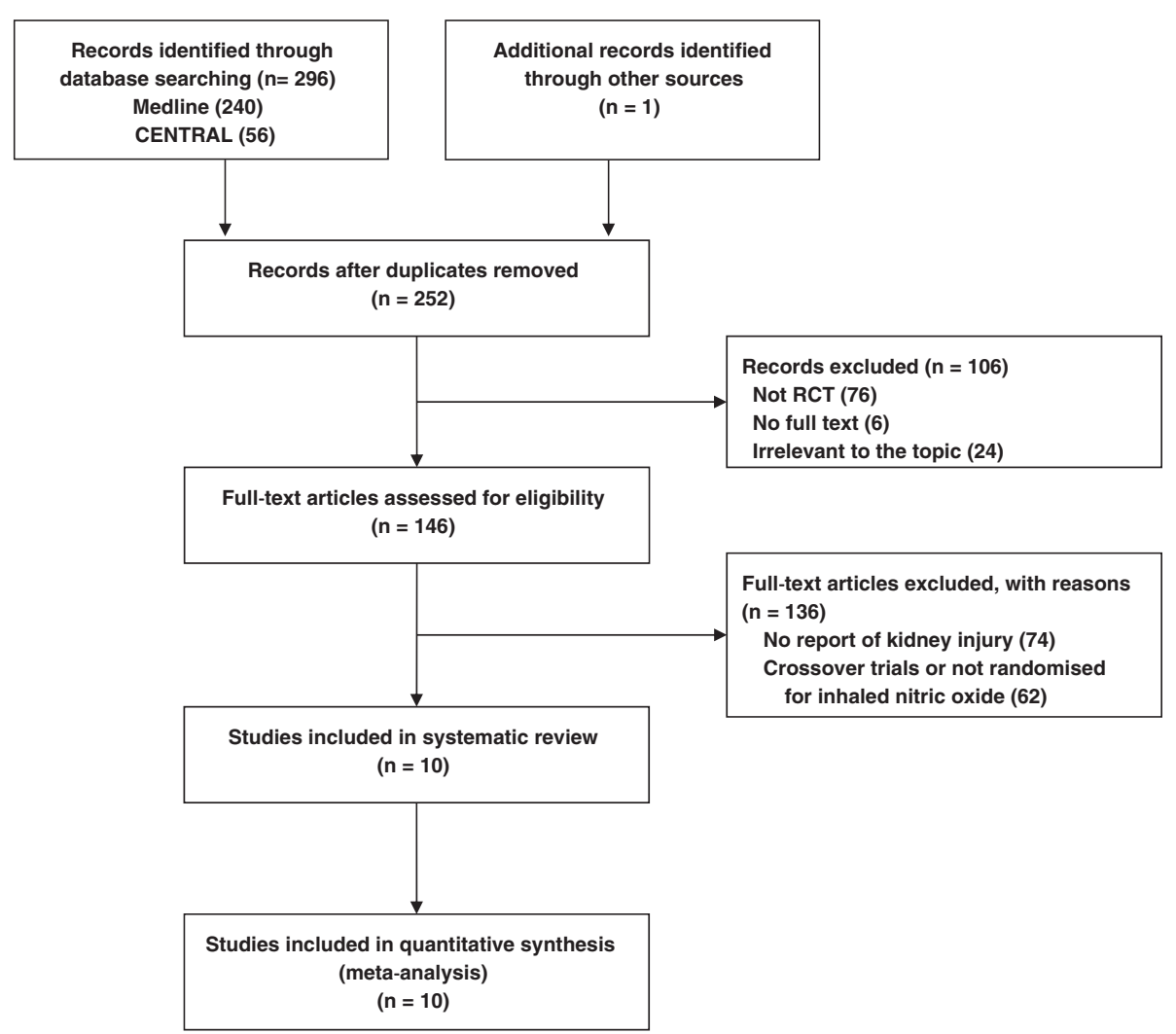

Figure 1 Study flow through this systematic review. RCT, randomized controlled trial.

The characteristics of the included studies are summarized in Table 1. The publication year ranged from 1998 to 2014, and included four studies on patients with ARDS, four studies on patients undergoing surgery, one study on neonates with hypoxemic respiratory failure, and one study on patients with sepsis. The administered dose and duration of iNO varied largely among these studies. In the ARDS trials, the dose of iNO shifted from a titrated dose of 1 to $40 \mathrm{ppm}$ in the 1990s to a fixed dose of $5 \mathrm{ppm}$ in the latest trial $[12,23]$. The treatment duration was longer in the ARDS studies ( $>7$ days) than in the non-ARDS studies ( $\leq 7$ days).

\section{Reporting of renal dysfunction}

Renal dysfunction in these trials was usually defined as an excess of creatinine level to a predefined level or the need for renal replacement therapy (Table 1). Among these trials, three reported the data of two different definitions of renal dysfunction. Notably, many clinical trials of iNO were excluded from this systematic review due to a lack of data on renal adverse effects, especially in the pediatric studies. Bleeding and neurological complications were the main concerns for the pediatric patients, and data on renal dysfunction were rarely reported in the safety outcomes.

\section{Quantitative data synthesis}

For the primary outcome of AKI with any severity (Figure 2), the pooled effect from 10 studies showed that iNO therapy significantly increased the risk of AKI with an RR of 1.40 (95\% CI, 1.06 to $\left.1.83, P=0.02, I^{2}=0 \%\right)$. The study by Payen [21] accounted for $39 \%$ of meta-analysis weight but was only published with an abstract. After omitting this influential study, the effect estimate remained similar (RR, 1.42, 95\% CI, 1.003 to $2.01, P=0.048$, $\left.I^{2}=0 \%\right)$. The statistical heterogeneity was low among the analyses.

For the endpoint of AKI requiring renal replacement therapy (Figure 3), iNO also increased the risk with a RR of 1.51 ( $95 \% \mathrm{CI}, 1.09$ to $2.11, P=0.01, I^{2}=0 \%$ ). The effect estimate became larger after we omitted the influential study by Payen (RR, $1.76,95 \% \mathrm{CI}, 1.05$ to $2.93, P=0.03$, $\left.I^{2}=0 \%\right)$.

Due to the presence of sparse data and imbalance of trial size, sensitivity analysis was performed to evaluate the influence of data synthesis methods on the estimate of summary effect. The effect estimate by the Peto method was similar to that obtained by the primary analysis with a random-effects model (Table 2).

Figure 4 shows a funnel plot based on the primary outcome. The asymmetry of the funnel plot on visual 
Table 1 Details of the included randomized controlled trials

\begin{tabular}{|c|c|c|c|c|c|c|c|c|}
\hline \multirow[t]{2}{*}{ Study (year) } & \multirow[t]{2}{*}{ Country } & \multirow[t]{2}{*}{ Study population } & \multirow[t]{2}{*}{ Protocol of iNO therapy } & \multirow[t]{2}{*}{$\begin{array}{l}\text { Mean iNO } \\
\text { dosage }\end{array}$} & \multirow[t]{2}{*}{ Age, years } & \multirow[t]{2}{*}{$\begin{array}{l}\text { Definition of acute } \\
\text { kidney injury (AKI) }\end{array}$} & \multicolumn{2}{|c|}{$\begin{array}{l}\text { Number of } A K I / \text { number } \\
\text { of cases }\end{array}$} \\
\hline & & & & & & & $\mathrm{iNO}$ & Control \\
\hline \multirow[t]{2}{*}{ Dellinger (1998) [12] } & \multirow[t]{2}{*}{ USA } & \multirow[t]{2}{*}{ ARDS } & \multirow{2}{*}{$\begin{array}{l}1.25,5.0,20.0,40.0 \text {, or } 80.0 \text { ppm iNO for } \\
28 \text { days or till } \mathrm{FiO}_{2}<0.5\end{array}$} & \multirow[t]{2}{*}{21 ppm } & \multirow[t]{2}{*}{48} & Creatinine $>2 \mathrm{mg} / \mathrm{dL}$ & $20 / 120$ & $7 / 57$ \\
\hline & & & & & & Creatinine $\geq 3.5 \mathrm{mg} / \mathrm{dL}$ & $13 / 120$ & $5 / 57$ \\
\hline \multirow[t]{2}{*}{ Lundin (1999) [20] } & \multirow[t]{2}{*}{$\begin{array}{l}11 \text { European } \\
\text { countries }\end{array}$} & \multirow[t]{2}{*}{ ARDS } & \multirow{2}{*}{$\begin{array}{l}1 \text { to } 40 \text { ppm iNO at the lowest effective } \\
\text { dose for up to } 30 \text { days or until an end point } \\
\text { was reached }\end{array}$} & \multirow[t]{2}{*}{9 ppm } & \multirow[t]{2}{*}{57} & $\begin{array}{l}\text { Creatinine }>3.4 \mathrm{mg} / \mathrm{dL} \text { or } \\
\text { RRT }\end{array}$ & $28 / 80$ & $12 / 74$ \\
\hline & & & & & & Incident RRT & $23 / 84$ & $10 / 79$ \\
\hline Kinsella (1999) [22] & USA & $\begin{array}{l}\text { Neonate hypoxemic } \\
\text { respiratory failure }\end{array}$ & 5 ppm for 7 days & $5 \mathrm{ppm}$ & 27 weeks & Renal failure & $2 / 48$ & $2 / 32$ \\
\hline Payen (1999) [21] & Europe & ARDS & 10 ppm till PF $>250$, median 5 days & 10 ppm & $\begin{array}{l}\text { Not } \\
\text { reported }\end{array}$ & RRT & $33 / 98$ & $26 / 105$ \\
\hline \multirow[t]{2}{*}{ Taylor (2004) [23] } & \multirow[t]{2}{*}{ USA } & \multirow[t]{2}{*}{ ARDS } & \multirow{2}{*}{$\begin{array}{l}5 \text { ppm until } 28 \text { days, discontinuation } \\
\text { of assisted breathing, or death }\end{array}$} & \multirow[t]{2}{*}{$5 \mathrm{ppm}$} & \multirow[t]{2}{*}{50} & Creatinine $\geq 3 \mathrm{mg} / \mathrm{dL}$ & $12 / 192$ & 8/193 \\
\hline & & & & & & Creatinine $\geq 3.5 \mathrm{mg} / \mathrm{dL}$ & $10 / 192$ & $6 / 193$ \\
\hline Perrin (2006) [24] & France & $\begin{array}{l}\text { Lung } \\
\text { transplantation }\end{array}$ & 20 ppm for $12 \mathrm{~h}$ & 20 ppm & 35 & RRT & $1 / 15$ & $1 / 15$ \\
\hline Potapov (2011) [26] & USA and Germany & Cardiac surgery & $40 \mathrm{ppm}$ for $48 \mathrm{~h}$ & $40 \mathrm{ppm}$ & 56 & RRT & $10 / 73$ & $8 / 77$ \\
\hline $\begin{array}{l}\text { Fernandes (2011) } \\
{[25]}\end{array}$ & Brazil & Cardiac surgery & $10 \mathrm{ppm}$ for $48 \mathrm{~h}$ & 10 ppm & 46 & Urine output $<0.3 \mathrm{ml} / \mathrm{kg} / \mathrm{h}$ & $0 / 14$ & $1 / 15$ \\
\hline Lang (2014) [28] & USA & Liver transplantation & 80 ppm during the operative phase & 80 ppm & 56 & Renal dysfunction & $3 / 40$ & $7 / 40$ \\
\hline Trzeciak (2014) [27] & USA & Sepsis & 40 ppm for $6 \mathrm{~h}$ & 40 ppm & 59 & RRT & $2 / 26$ & $1 / 23$ \\
\hline
\end{tabular}

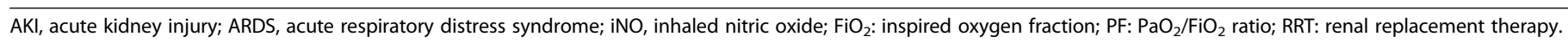




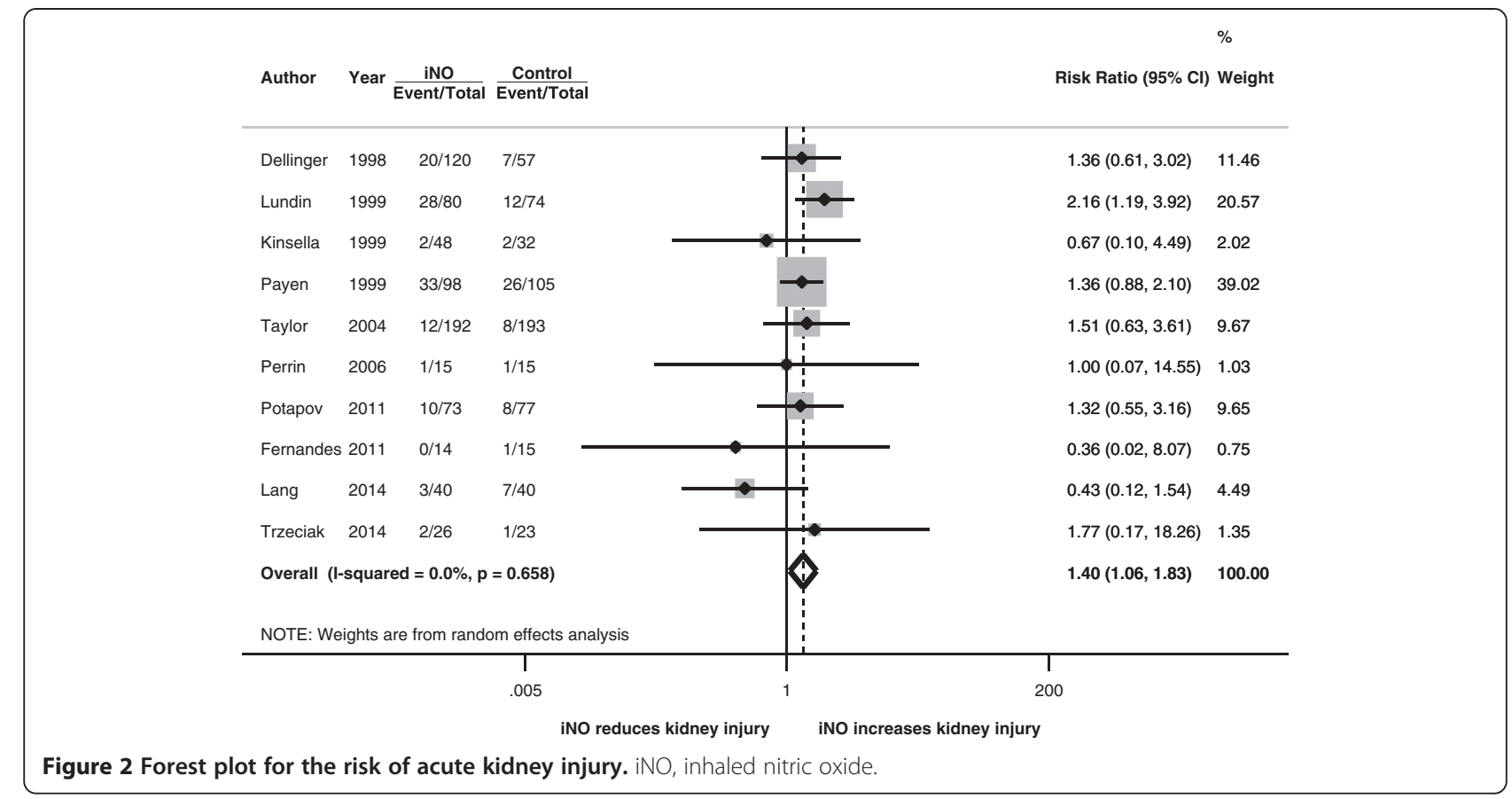

inspection implied a lack of studies in which iNO increased the risk of AKI. This suggests that the pooled effect from the current data may underestimate the effect size of the risk. However, the statistical test for publication bias, Egger's test $(P=0.33)$, did not reach statistical significance.

The risk of AKI associated with iNO therapy varied among the different populations (Table 3). The risk was significantly increased in the patients with ARDS (RR,
$1.55,95 \% \mathrm{CI}, 1.15$ to $2.09, P=0.005)$, but not in patients without ARDS (RR, 0.9, 95\%CI, 0.49 to $1.67, P=0.75$ ). Among the patients with ARDS, the risk difference for AKI between iNO and control groups was 0.067 (95\% CI, 0.000 to $0.135, P=0.05, I^{2}=50 \%$ ), and the number needed-to-harm to cause one additional AKI was 15 .

To test the dose-response relationship between iNO and the risk of AKI, we performed stratified analysis by duration and dosage of iNO therapy. Prolonged use of

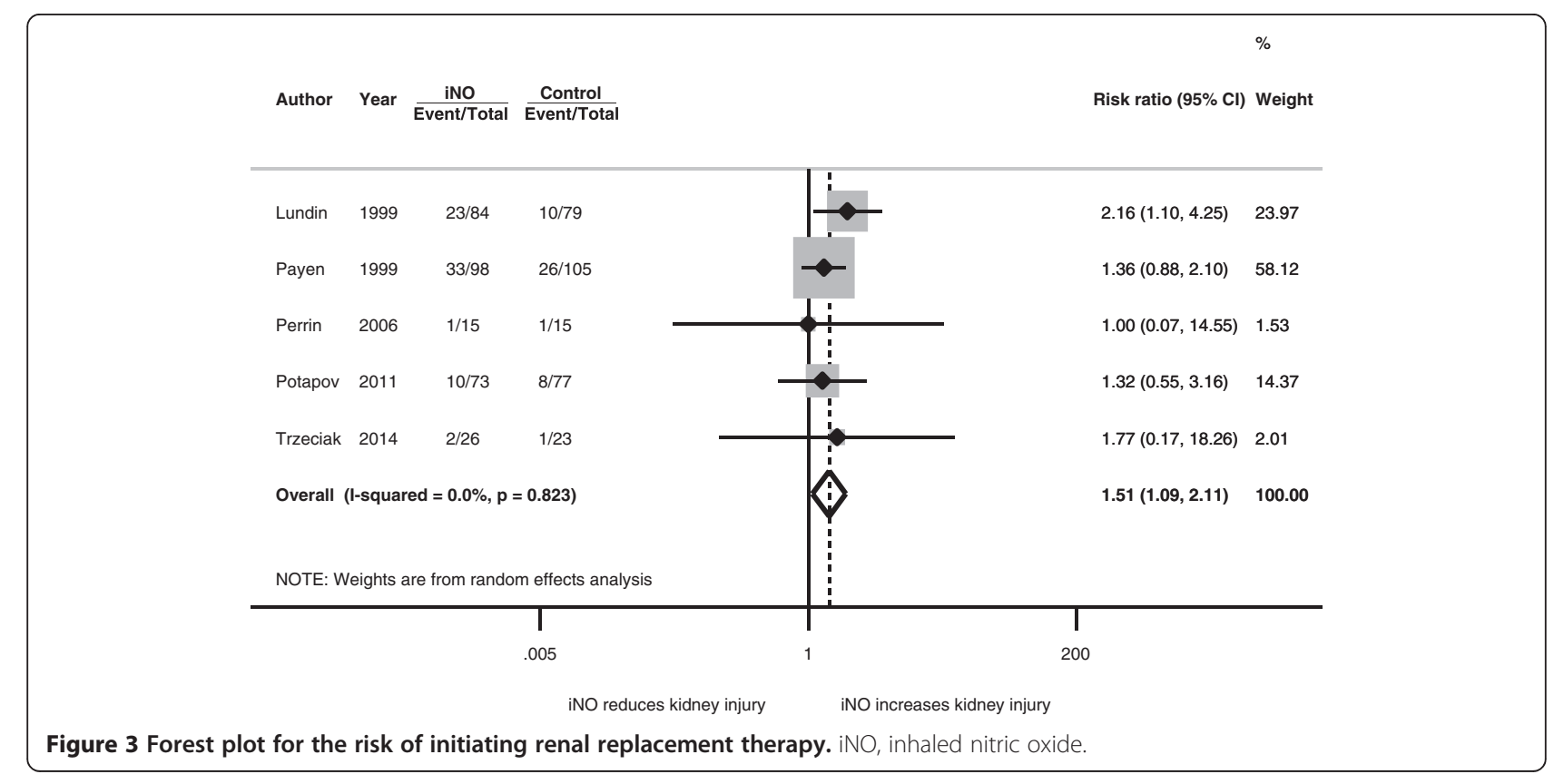


Table 2 Sensitivity analysis by different data synthesis methods

\begin{tabular}{|c|c|c|c|c|c|}
\hline Outcome measures & $\begin{array}{l}\text { Number of studies } \\
\text { (number of patients) }\end{array}$ & Statistical model & Effect size $(95 \% \mathrm{Cl})$ & $P$-value (test for effect) & Heterogeneity \\
\hline \multirow[t]{3}{*}{ Acute kidney injury } & $10(1337)$ & RR, random-effects & 1.40 (1.06 to 1.83$)$ & 0.02 & $P^{2}=0 \%$ \\
\hline & & OR, random-effects & 1.50 (1.07 to 2.09$)$ & 0.02 & $P^{2}=0 \%$ \\
\hline & & OR, Peto & 1.48 (1.07 to 2.05$)$ & 0.02 & $P^{2}=0 \%$ \\
\hline \multirow[t]{3}{*}{ Initiation of renal replacement therapy } & $5(595)$ & $\mathrm{RR}$, random-effects & 1.51 (1.09 to 2.11$)$ & 0.01 & $P^{2}=0 \%$ \\
\hline & & OR, random-effects & 1.73 (1.13 to 2.65$)$ & 0.01 & $P^{2}=0 \%$ \\
\hline & & OR, Peto & $1.73(1.14$ to 2.41$)$ & 0.01 & $P^{2}=0 \%$ \\
\hline
\end{tabular}

$\mathrm{RR}$, risk ratio; $\mathrm{OR}$, odds ratio.

iNO ( $>7$ days) significantly increased the risk of AKI (RR, $1.55,95 \% \mathrm{CI}, 1.15$ to $2.09, P=0.005$, four studies), whereas short-term use did not (RR, 0.90, 95\% CI, 0.49 to $1.67, P=0.75$, six studies). Notably, the four studies involving the prolonged use of iNO are all ARDS studies. Table 4 summarizes the risk of renal dysfunction for different iNO exposure levels. We classified the included studies into three groups according to the cumulative dose in the stratified analysis. High cumulative dose of iNO significantly increased the risk of renal dysfunction but medium and low cumulative doses did not (Table 4). Figure 5 depicts the relationship between the risk of renal dysfunction and cumulative dose of iNO. Visual inspection suggested a possible association between the cumulative dose and risk of renal dysfunction but statistical test by meta-regression analysis was not significant due to small sample size $(P=0.10)$.

\section{Discussion}

This meta-analysis updated the evidence on the renal safety of iNO therapy in ARDS and non-ARDS populations. The study suggested that the risk of iNO-associated renal dysfunction differed between ARDS and non-ARDS populations. The results showed that iNO therapy was associated with a $40 \%$ increased risk of renal dysfunction and the observed effect was mainly attributed to ARDS studies with prolonged use of iNO. If treating ARDS patients with iNO the number needed-to-harm to cause one additional AKI was 15. Sensitivity analysis by different data pooling methods revealed consistent effect estimates, and publication bias analysis suggested that the risk may be underestimated. Clinicians should be aware of this side effect when using iNO to treat patients. Our review also found that the safety outcome of renal dysfunction was not universally reported across iNO trials, especially in non-ARDS studies. We suggest that future trials of iNO should report renal safety outcomes.

The risk of renal dysfunction associated with iNO therapy was first reported in an RCT of patients with ARDS, in which iNO was found to double the risk of the need for renal replacement therapy compared with controls [20]. However, this adverse effect did not raise much attention because subsequent trials of iNO reported no significant increase in the risk of renal dysfunction [12,23].

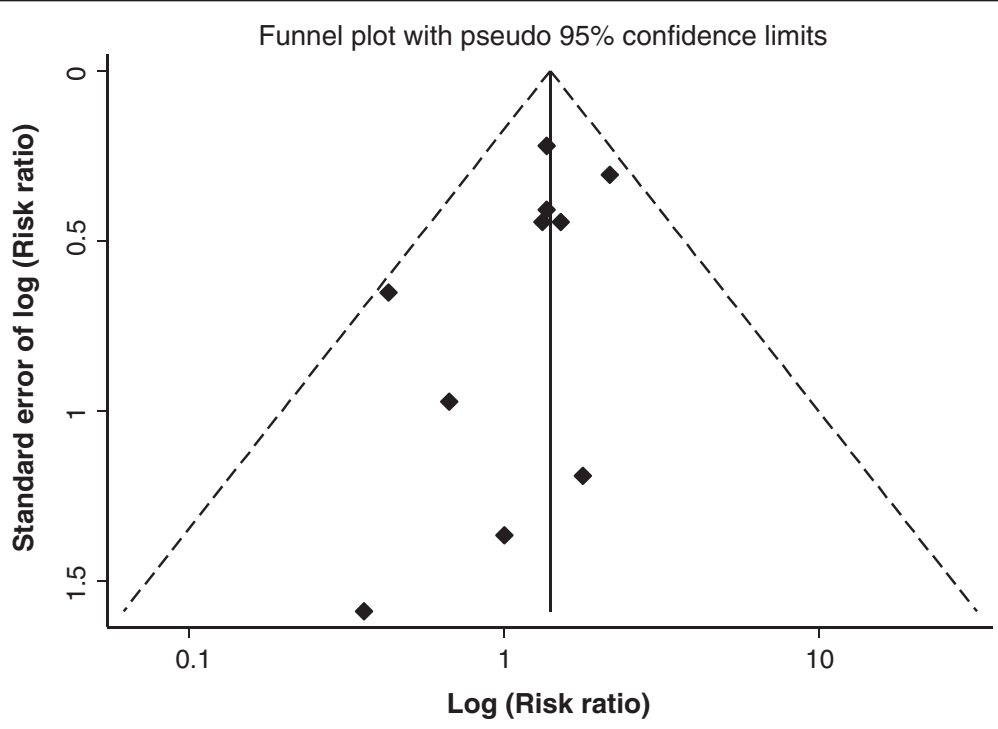

Figure 4 Funnel plot based on the primary outcome. 
Table 3 Subgroup analysis by study population

\begin{tabular}{lllll}
\hline Subgroups & $\begin{array}{l}\text { Number of studies } \\
\text { (number of patients) }\end{array}$ & Risk ratio of AKI (95\% Cl) & P-value (test for effect) & Heterogeneity \\
\hline ARDS & $4(919)$ & $1.55(1.15$ to 2.09$)$ & 0.005 & $P^{2}=0 \%$ \\
Non-ARDS & $6(418)$ & $0.90(0.49$ to 1.67$)$ & 0.75 & $P^{2}=0 \%$ \\
Surgery & $4(289)$ & $0.89(0.45$ to 1.75$)$ & 0.73 & $P^{2}=0 \%$ \\
Sepsis & $1(49)$ & $1.77(0.17$ to 18.26$)$ & 0.63 & Not applicable \\
Pediatric hypoxemic respiratory failure & $1(80)$ & $0.67(0.10$ to 4.49$)$ & 0.68 & Not applicable \\
\hline
\end{tabular}

AKI, acute kidney injury; ARDS, acute respiratory distress syndrome.

In 2007, Adhikari and colleagues reported that iNO was associated with renal dysfunction in a meta-analysis [13]. This meta-analysis only included ARDS trials because the primary study interest was the efficacy of iNO on ARDS [13]. The strengths of our study are the comprehensive evaluations of iNO-related renal dysfunction among patients with and without ARDS, the influence of different endpoints of renal dysfunction, and the dose-response relationship. Although our analysis suggests that iNO may increase the risk of renal dysfunction, it is not clear whether the increased risk is ARDS-specific or related to prolonged use of iNO. We were unable to clarify this in study-level analysis because the ARDS studies all involved the prolonged use of iNO.

Generating awareness of the nephrotoxicity of iNO has important implications for preventing AKI in the intensive care unit. Previous studies have shown that the development of AKI significantly increased mortality in patients with ARDS [29]. We suggest that intensivists should be cautious about the concurrent use of iNO with other nephrotoxic agents such as certain antibiotics, when treating ARDS. Renal function should be regularly monitored during iNO therapy to detect possible AKI early. In addition, the nephrotoxicity of iNO may partly explain why iNO therapy improves oxygenation and attenuates inflammation but confers no benefit on mortality in patients with ARDS [3,30,31]. The benefits of iNO may be counterbalanced by the increased risk of renal failure, because organ failure is positively associated with mortality [32].

The mechanism of iNO-related renal dysfunction remains unclear. Table 5 summarizes the findings of animal and physiological studies on this issue [9,33-38].
These studies all examined the effect of short-term exposure to iNO, and most reported that iNO had beneficial effects on renal function except for a swine study which reported that iNO promoted renal tubular apoptosis [33]. In this swine model, renal resorption capacity was significantly blunted by iNO, and this may have led to tubular and glomerular injury by means of tubuloglomerular feedback [33]. With respect to nitric oxide metabolites, nitric oxide inhalation increased serum levels of plasma cyclic guanosine monophosphate (cGMP), nitrate, and nitrite [39]. These nitric oxide metabolites may play a role in AKI development owing to the effects on protein nitrosation and raising oxidative load [40-42]. In an animal model of drug-induced nephrotoxicity, elevated nitrite and nitrate levels were observed with increasing oxidative activity [40]. The induced nephrotoxicity could be ameliorated by selective phosphodiesterase- 5 inhibitor by suppressing oxidative activity and nitrite and nitrate levels [40]. In addition, from the pathways of chemical reactions of nitric oxide in the lung, we speculate that oxidative injury caused by highly oxidant nitrogen compounds may also play a role in iNO-related kidney injury. Reactive nitrogen species such as nitrogen dioxide $\left(\mathrm{NO}_{2}\right)$ are highly oxidative compounds that are produced when iNO mixes with high concentrations of oxygen in the alveoli $[3,11]$. In patients with ARDS treated with iNO, the serum concentrations of $\mathrm{NO}_{2}$ have been positively associated with the dose of iNO administered [12]. It has also been shown that systemically circulating $\mathrm{NO}_{2}$ may lead to cytotoxic effects on renal parenchymal cells [43]. This hypothesis of oxidative injury by reactive nitrogen species may also explain why nephrotoxicity tends to develop in patients with ARDS receiving iNO therapy, as

Table 4 Dose-response relationship between inhaled nitric oxide and the risk of acute kidney injury

\begin{tabular}{llllll}
\hline Cumulative dose of inhaled nitric oxide & $\begin{array}{l}\text { Numer of studies } \\
\text { (number of patients) }\end{array}$ & Risk ratio of AKI (95\% Cl) & $\begin{array}{l}\boldsymbol{P} \text {-value } \\
\text { (test for effect) }\end{array}$ & Heterogeneity & References \\
\hline Low & $2(109)$ & $0.56(0.11$ to 2.86$)$ & 0.49 & $P^{2}=0 \%$ & {$[22,25]$} \\
Medium & $3(159)$ & $0.64(0.23$ to 1.81$)$ & 0.40 & $P^{2}=0 \%$ & {$[24,27,28]$} \\
High & $5(1069)$ & $1.52(1.14$ to 2.02$)$ & 0.004 & $P^{2}=0 \%$ & {$[12,20,21,23,26]$} \\
\hline
\end{tabular}

AKI, acute kidney injury. 


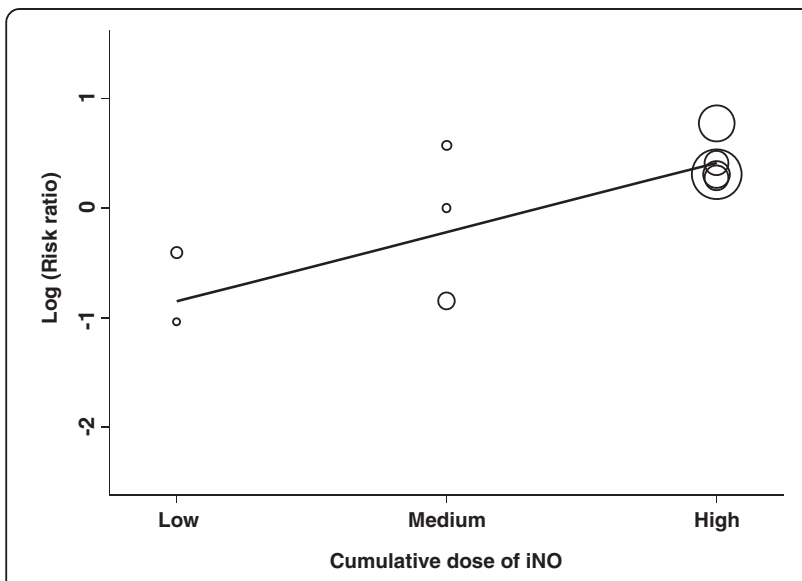

Figure 5 Bubble plot with fitted meta-regression line depicting the relationship between the risk of renal dysfunction and cumulative dose of inhaled nitric oxide (Ino).

these patients usually receive high-concentration oxygen therapy, which may facilitate the production of reactive nitrogen species. Animal studies are needed to test this hypothesis.

\section{Limitations}

Our study has limitations. First, the included number of studies and the number of cases in individual studies are small for the non-ARDS trials. This may have limited the statistical power of our subgroup analysis and meta-regression. Second, although the level of statistical heterogeneity was very low in all of our analyses, the heterogeneity on exposure (treatment duration and dosage of iNO) should not be overlooked. Third, death was a competing risk factor in our analysis. However, we were unable to adjust for this competing risk in studylevel analysis. Individual data are needed to conduct such analyses.

\section{Conclusion}

This meta-analysis updated the evidence on the renal safety of iNO therapy in ARDS and non-ARDS populations. Our results suggest that iNO therapy substantially increases the risk of renal dysfunction. It remains unclear whether this markedly increased risk is disease-specific in ARDS or related to prolonged use of iNO. Further studies are needed to clarify this issue. We suggest that renal function should be monitored during iNO therapy and that future clinical trials of iNO should evaluate renal safety.

\section{Key messages}

- Previous studies have shown that iNO has a good safety profile and favorable effects on renal and splanchnic perfusion; however, iNO therapy has been reported to be associated with renal dysfunction.

- This meta-analysis updated the evidence regarding renal safety of iNO therapy. The study suggested that the risk of iNO-associated renal dysfunction differed between ARDS and non-ARDS populations. Nitric oxide inhalation may increase the risk of renal dysfunction, especially with prolonged use and in patients with ARDS.

- The safety outcome of renal dysfunction was not universally reported across iNO trials, especially in non-ARDS studies. We suggest monitoring renal function during iNO therapy, and that future trials of iNO should evaluate renal safety.

Table 5 Animal and human studies investigating the effects of inhaled nitric oxide (iNO) on the kidneys

\begin{tabular}{|c|c|c|c|}
\hline Study (year) & Species & Protocols of iNO & Main findings \\
\hline \multirow[t]{2}{*}{ Valvini (1995) [38] } & Human & $\begin{array}{l}40 \text { ppm for } 3 \text { days followed by } \\
90 \text { ppm for } 2 \text { days }\end{array}$ & $\begin{array}{l}\text { 1. Inhaling } 40 \text { ppm nitric oxide would result in a daily nitrogen oxide } \\
\text { load of about } 25 \mathrm{mmol} \text {. }\end{array}$ \\
\hline & & & $\begin{array}{l}\text { 2. Impairment of renal function would cause an increase in serum } \\
\text { nitrogen oxides. }\end{array}$ \\
\hline Troncy (1997) [9] & Swine & 40 ppm iNO & $\begin{array}{l}\text { Inhaled nitric oxide increased renal blood flow, glomerular filtration } \\
\text { rate and urinary flow. }\end{array}$ \\
\hline \multirow[t]{2}{*}{ Preiser (1998) [37] } & Human & 1 to 20 ppm & 1. Renal excretion of $\mathrm{NO}_{2}^{-}$and $\mathrm{NO}_{3}^{-}$was unaltered by nitric oxide inhalation. \\
\hline & & & $\begin{array}{l}\text { 2. Long-term nitric oxide inhalation was associated with a consistent } \\
\text { increase in the } \mathrm{NO}_{3}^{-} \text {plasma concentration. }\end{array}$ \\
\hline Wraight (2001) [36] & Human & 40 ppm for $2 \mathrm{~h}$ & Inhaled nitric oxide may alter tubular salt and water resorbtion. \\
\hline Kielbasa (2001) [35] & Rat & 49 or 107 ppm iNO for $4 \mathrm{~h}$ & $\begin{array}{l}\text { High dose of iNO increased nitric oxide synthase III protein expression, } \\
\text { and nitrotyrosine and phosphotyrosine immunoreactivity. }\end{array}$ \\
\hline Da (2007) [34] & Swine & 30 ppm iNO for $3.5 \mathrm{~h}$ & Decreased swelling and necrosis of glomeruli. \\
\hline \multirow[t]{2}{*}{ Gozdzik (2009) [33] } & Swine & 40 ppm iNO for $30 \mathrm{~h}$ & 1. Transient natriuretic effect. \\
\hline & & & 2. Renal tubular apoptosis promotion after $30 \mathrm{~h}$ of iNO treatment. \\
\hline Göranson (2014) [44] & Swine & 30 ppm iNO for $30 \mathrm{~h}$ & $\begin{array}{l}\text { Combined therapy with iNO and intravenous steroid is associated with } \\
\text { partial protection of kidney function. }\end{array}$ \\
\hline
\end{tabular}




\section{Additional files}

\section{Additional file 1: Details of the search strategy and results. Additional file 2: Quality assessment using the Cochrane risk of bias tool.}

\section{Abbreviations}

AKI: acute kidney injury; ARDS: acute respiratory distress syndrome; iNO: inhaled nitric oxide; OR: odds ratio; PRISMA: Preferred Reporting Items for Systematic Reviews and Meta-Analyses; RCT: randomized controlled trial; RR: risk ratio; RRT: renal replacement therapy.

\section{Competing interests}

The authors declare that they have no competing interests.

\section{Authors' contributions}

Study concept and design: SYR and MSL. Acquisition of data: SYR and TMH. Analysis and interpretation of data: SYR, TMH, HYW, HDW, CJY and MSL. Drafting the article: SYR, TMH, HYW, HDW and CJY. All authors revised the manuscript for important intellectual content. All authors read and approved the manuscript.

\section{Acknowledgements}

Dr Sheng-Yuan Ruan was supported in part by a research grant of the Ministry of Science and Technology in Taiwan (103-2314-B-002 -153 -MY3).

\section{Author details}

${ }^{1}$ Institute of Epidemiology and Preventive Medicine, National Taiwan University, No.17 Xu-Zhou Road, Taipei 10020, Taiwan. 'Division of Pulmonary and Critical Care Medicine, Department of Internal Medicine, National Taiwan University Hospital, Taipei, Taiwan. ${ }^{3}$ Department of Internal Medicine, Far Eastern Memorial Hospital, New Taipei City, Taiwan.

Received: 4 December 2014 Accepted: 13 March 2015

Published online: 03 April 2015

\section{References}

1. Palmer RM, Ferrige AG, Moncada S. Nitric oxide release accounts for the biological activity of endothelium-derived relaxing factor. Nature. 1987;327:524-6.

2. Pepke-Zaba J, Higenbottam TW, Dinh-Xuan AT, Stone D, Wallwork J. Inhaled nitric oxide as a cause of selective pulmonary vasodilatation in pulmonary hypertension. Lancet. 1991:338:1173-4.

3. Griffiths MJ, Evans TW. Inhaled nitric oxide therapy in adults. N Engl J Med. 2005:353:2683-95.

4. Rimar S, Gillis CN. Selective pulmonary vasodilation by inhaled nitric oxide is due to hemoglobin inactivation. Circulation. 1993:88:2884-7.

5. Spieth PM, Zhang H. Pharmacological therapies for acute respiratory distress syndrome. Curr Opin Crit Care. 2014;20:113-21.

6. Gayat E, Mebazaa A. Pulmonary hypertension in critical care. Curr Opin Crit Care. 2011;17:439-48.

7. Kumar P. Use of inhaled nitric oxide in preterm infants. Pediatrics. 2014;133:164-70.

8. McMahon TJ, Doctor A. Extrapulmonary effects of inhaled nitric oxide: role of reversible S-nitrosylation of erythrocytic hemoglobin. Proc Am Thorac Soc. 2006:3:153-60.

9. Troncy E, Francoeur M, Salazkin I, Yang F, Charbonneau M, Leclerc G, et al. Extra-pulmonary effects of inhaled nitric oxide in swine with and without phenylephrine. Br J Anaesth. 1997;79:631-40.

10. Ng ES, Jourd'heuil D, McCord JM, Hernandez D, Yasui M, Knight D, et al. Enhanced S-nitroso-albumin formation from inhaled $\mathrm{NO}$ during ischemia/ reperfusion. Circ Res. 2004;94:559-65.

11. Weinberger $B$, Laskin $D L$, Heck DE, Laskin JD. The toxicology of inhaled nitric oxide. Toxicol Sci. 2001;59:5-16.

12. Dellinger RP, Zimmerman JL, Taylor RW, Straube RC, Hauser DL, Criner GJ, et al. Effects of inhaled nitric oxide in patients with acute respiratory distress syndrome: results of a randomized phase II trial. Inhaled Nitric Oxide in ARDS Study Group. Crit Care Med. 1998;26:15-23.
13. Adhikari NK, Burns KE, Friedrich JO, Granton JT, Cook DJ, Meade MO. Effect of nitric oxide on oxygenation and mortality in acute lung injury: systematic review and meta-analysis. BMJ. 2007;334:779

14. Moher D, Liberati A, Tetzlaff J, Altman DG. Preferred reporting items for systematic reviews and meta-analyses: the PRISMA statement. PLoS Med. 2009;6:e1000097.

15. Higgins JP, Altman DG, Gotzsche PC, Juni P, Moher D, Oxman AD, et al. The Cochrane Collaboration's tool for assessing risk of bias in randomised trials. BMJ. 2011;343:d5928.

16. Harrison RJ, Bradburn MJ, Deeks JJ, Harbord RM, Altman DG, Sterne JAC. Metan: fixed- and random-effects meta-analysis. The Stata Journal. 2008:8:3-28.

17. Bradburn MJ, Deeks JJ, Berlin JA, Russell LA. Much ado about nothing: a comparison of the performance of meta-analytical methods with rare events. Stat Med. 2007;26:53-77.

18. Higgins JP, Thompson SG, Deeks JJ, Altman DG. Measuring inconsistency in meta-analyses. BMJ. 2003;327:557-60

19. Egger M, Davey Smith G, Schneider M, Minder C. Bias in meta-analysis detected by a simple, graphical test. BMJ. 1997:315:629-34.

20. Lundin S, Mang H, Smithies M, Stenqvist O, Frostell C. Inhalation of nitric oxide in acute lung injury: results of a European multicentre study. The European study group of inhaled nitric oxide. Intensive Care Med. 1999;25:911-9.

21. Payen D, Vallet B, Group d'étude du NO dans I'ARDS. Results of the French prospective multicentric randomized double-blind placebo-controlled trial on inhaled nitric oxide (NO) in ARDS [Abstract]. Intensive Care Med. 1999;25:166.

22. Kinsella JP, Walsh WF, Bose CL, Gerstmann DR, Labella JJ, Sardesai S, et al. Inhaled nitric oxide in premature neonates with severe hypoxaemic respiratory failure: a randomised controlled trial. Lancet. 1999;354:1061-5.

23. Taylor RW, Zimmerman JL, Dellinger RP, Straube RC, Criner GJ, Davis Jr K et al. Low-dose inhaled nitric oxide in patients with acute lung injury: a randomized controlled trial. JAMA. 2004;291:1603-9.

24. Perrin G, Roch A, Michelet P, Reynaud-Gaubert M, Thomas P, Doddoli C, et al. Inhaled nitric oxide does not prevent pulmonary edema after lung transplantation measured by lung water content: a randomized clinical study. Chest. 2006;129:1024-30

25. Fernandes JL, Sampaio RO, Brandao CM, Accorsi TA, Cardoso LF, Spina GS, et al. Comparison of inhaled nitric oxide versus oxygen on hemodynamics in patients with mitral stenosis and severe pulmonary hypertension after mitral valve surgery. Am J Cardiol. 2011;107:1040-5.

26. Potapov E, Meyer D, Swaminathan M, Ramsay M, El Banayosy A, Diehl C, et al. Inhaled nitric oxide after left ventricular assist device implantation: a prospective, randomized, double-blind, multicenter, placebo-controlled trial. J Heart Lung Transplant. 2011;30:870-8.

27. Trzeciak S, Glaspey LJ, Dellinger RP, Durflinger P, Anderson K, Dezfulian C, et al. Randomized controlled trial of inhaled nitric oxide for the treatment of microcirculatory dysfunction in patients with sepsis. Crit Care Med. 2014;42:2482-92

28. Lang Jr JD, Smith AB, Brandon A, Bradley KM, Liu Y, Li W, et al. A randomized clinical trial testing the anti-inflammatory effects of preemptive inhaled nitric oxide in human liver transplantation. PLoS One. 2014:9:e86053

29. Soto GJ, Frank AJ, Christiani DC, Gong MN. Body mass index and acute kidney injury in the acute respiratory distress syndrome. Crit Care Med. 2012;40:2601-8

30. Adhikari NK, Dellinger RP, Lundin S, Payen D, Vallet B, Gerlach $\mathrm{H}$, et al. Inhaled nitric oxide does not reduce mortality in patients with acute respiratory distress syndrome regardless of severity: systematic review and meta-analysis*. Crit Care Med. 2014:42:404-12.

31. Afshari A, Brok J, Moller AM, Wetterslev J. Inhaled nitric oxide for acute respiratory distress syndrome and acute lung injury in adults and children: a systematic review with meta-analysis and trial sequential analysis. Anesth Analg. 2011:112:1411-21.

32. Sakr Y, Lobo SM, Moreno RP, Gerlach H, Ranieri VM, Michalopoulos A, et al Patterns and early evolution of organ failure in the intensive care unit and their relation to outcome. Crit Care. 2012;16:R222.

33. Gozdzik W, Albert J, Harbut P, Zielinski S, Ryniak S, Lindwall R, et al. Prolonged exposure to inhaled nitric oxide transiently modifies tubular function in healthy piglets and promotes tubular apoptosis. Acta Physiol (Oxf). 2009;195:495-502. 
34. Da J, Chen L, Hedenstierna G. Nitric oxide up-regulates the glucocorticoid receptor and blunts the inflammatory reaction in porcine endotoxin sepsis. Crit Care Med. 2007;35:26-32.

35. Kielbasa WB, Fung HL. Systemic biochemical effects of inhaled NO in rats: increased expressions of NOS III, nitrotyrosine-, and phosphotyrosineimmunoreactive proteins in liver and kidney tissues. Nitric Oxide. 2001:5:587-94.

36. Wraight WM, Young JD. Renal effects of inhaled nitric oxide in humans. Br J Anaesth. 2001;86:267-9.

37. Preiser JC, De Backer D, Debelle F, Vray B, Vincent JL. The metabolic fate of long-term inhaled nitric oxide. J Crit Care. 1998;13:97-103.

38. Valvini EM, Young JD. Serum nitrogen oxides during nitric oxide inhalation. Br J Anaesth. 1995;74:338-9.

39. Lukaszewicz AC, Mebazaa A, Callebert J, Mateo J, Gatecel C, Kechiche H, et al. Lack of alteration of endogenous nitric oxide pathway during prolonged nitric oxide inhalation in intensive care unit patients. Crit Care Med. 2005;33:1008-14.

40. Morsy MA, Ibrahim SA, Amin EF, Kamel MY, Rifaai RA, Hassan MK. Sildenafil ameliorates gentamicin-induced nephrotoxicity in rats: role of iNOS and eNOS. J Toxicol. 2014;2014:489382.

41. Blanchard B, Dendane M, Gallard JF, Houee-Levin C, Karim A, Payen D, et al. Oxidation, nitrosation, and nitration of serotonin by nitric oxide-derived nitrogen oxides: biological implications in the rat vascular system. Nitric Oxide. 1997;1:442-52.

42. Whitaker RM, Wills LP, Stallons LJ, Schnellmann RG. cGMP-selective phosphodiesterase inhibitors stimulate mitochondrial biogenesis and promote recovery from acute kidney injury. J Pharmacol Exp Ther. 2013;347:626-34

43. Han M, Guo Z, Li G, Sang N. Nitrogen dioxide inhalation induces genotoxicity in rats. Chemosphere. 2013;90:2737-42.

44. Goranson SP, Gozdzik W, Harbut P, Ryniak S, Zielinski S, Haegerstrand CG, et al. Organ dysfunction among piglets treated with inhaled nitric oxide and intravenous hydrocortisone during prolonged endotoxin infusion. PLoS One. 2014;9:e96594.

\section{Submit your next manuscript to BioMed Central and take full advantage of:}

- Convenient online submission

- Thorough peer review

- No space constraints or color figure charges

- Immediate publication on acceptance

- Inclusion in PubMed, CAS, Scopus and Google Scholar

- Research which is freely available for redistribution 